\title{
A Study of Bacterial Flora Present on Disinfected Crash Cart Laryngoscopes
}

\author{
Mausum Ranjan Behera ${ }^{1}$, Tushar Bhutada ${ }^{2}$, Kundan Kumar Sahu ${ }^{3}$, Sarita Otta ${ }^{3, *}$ \\ ${ }^{1}$ Hope Diagnostic and Research Centre, Bhubaneswar, India \\ ${ }^{2}$ Department of Forensic Medicine and Toxicology, KIIT University, Odisha, India \\ ${ }^{3}$ Department of Microbiology, IMS and SUM Hospital, Siksha 'O' Anusandhan (Deemed to be) University, Odisha, India
}

Received September 8, 2021; Revised November 24, 2021; Accepted December 13, 2021

\section{Cite This Paper in the following Citation Styles}

(a): [1] Mausum Ranjan Behera, Tushar Bhutada, Kundan Kumar Sahu, Sarita Otta , "A Study of Bacterial Flora Present on Disinfected Crash Cart Laryngoscopes," Universal Journal of Public Health, Vol. 9, No. 6, pp. 431 - 435, 2021. DOI: 10.13189/ujph.2021.090610.

(b): Mausum Ranjan Behera, Tushar Bhutada, Kundan Kumar Sahu, Sarita Otta (2021). A Study of Bacterial Flora Present on Disinfected Crash Cart Laryngoscopes. Universal Journal of Public Health, 9(6), 431 - 435. DOI: 10.13189/ujph.2021.090610.

Copyright $@ 2021$ by authors, all rights reserved. Authors agree that this article remains permanently open access under the terms of the Creative Commons Attribution License 4.0 International License

\begin{abstract}
Background: Laryngoscope is an instrument to facilitate placement of endotracheal tube which finds its use both in OTs and in crash carts for emergency resuscitation of patients. The blade of the instrument comes in contact with the mucosal surface during this procedure. Yet, there is an absence of clear cut guidelines for disinfection of different parts (blade and handle) of this instrument. Materials and methods: This observational prospective study was conducted over a period of 5 months on previously used and disinfected laryngoscopes placed in the crash carts of various areas (emergency, ICUs) of our hospital. Swabs were collected from three different parts of each laryngoscope: surface of the blade (A), front part of the handle top (B), and front part of the handle's knurled surface (C). Bacterial growth and identification were noted using standard microbiological techniques. Data were entered and analyzed using standard MS Excel sheet. Results: In the study, 213 samples (71 each from A, B, C sites) were obtained from laryngoscopes from various areas of the hospital of which $32.4 \%$ were contaminated. The highest percentage of contaminated laryngoscopes belonged to Emergency department, a known high throughput area. Swabs from blades were positive in $16.9 \%(12 / 71)$ cases, from light in $14.08 \%$ (10/71) cases and from handle in 18.3\% (13/71) cases. Among the organisms isolated, Coagulase negative Staphylococcus was the commonest (37.1\%) followed by MSSA (22.9\%) and MRSA (20\%) from various sites of the
\end{abstract}

laryngoscopes. Conclusion: A sensitization towards proper cleaning of laryngoscopes from crash carts is a must. Centralized disinfection services of all the parts of this instrument are a must for ensuring proper sterility.

Keywords Laryngoscope Handles, Disinfection, Crash Carts, High Level Disinfection

\section{Introduction}

Laryngoscope is an instrument containing a handle and blade with a light source useful to visualize the vocal cord to facilitate placement of endotracheal tube which finds its use in OTs during general anesthesia and in crash carts for emergency resuscitation of patients. Esler [1] in a recent survey of decontamination of laryngoscopes in the United Kingdom (UK) concluded that 'there appears to be no rationale regarding the aim of laryngoscope cleaning or agreed methods to achieve that aim'. The blade of the instrument comes in contact with mucosal surfaces while handle stays is in touch with the blade during storage. Yet, there is an absence of clear cut guidelines for disinfection of different parts of this instrument. In this study, we attempt to note the bacterial contamination of the different parts of the ready to use instrument in our set up. 


\section{Material and Methods}

The present study was conducted in Department of Microbiology in IMS and SUM Hospital a tertiary care teaching hospital in Eastern part of India. This is an observational, prospective study conducted over a period of 5 months from January to May 2021, to find out the thoroughness of cleaning of the laryngoscope used in the crash carts of various areas (emergency, ICUs). For catering to huge requirement of ICUs because of the heavy foot fall our hospital has many different ICUs designated as Burn ICU (BICU), Gastrosurgery ICU (GICU), Neurosurgical ICU(NSICU), Surgical ICU (SICU), Medicine ICU (MICU). The ICUs were manned by different sets of doctors, paramedical staffs and attendants dedicated for each area. We included cleaned laryngoscope as identified by the nursing in-charge which was ready to use after previous use. Cleaning of the laryngoscope is done in the same area as that of use; first wiping with sterile gauze under running tap water, and then blade was wiped with cotton ball dipped in with 70\% isopropyl alcohol. The cleaning procedure is mandatorily done following each use following which it was allowed to dry and placed in a cotton warp or a designated box in the crash carts. Laryngoscopes that were not disinfected and unused instruments after collection of previous swab were excluded from the study. Laryngoscopes in pediatric and neonatal populations were also not included because of the difference in structure and disinfection practices in our hospital. Swabs were collected from three different parts of each laryngoscope i.e. (A) surface of the blade, (B) front part of the handle top, and (C) front part of the handle's knurled surface (Figure 1). Swabs (Himedia) pre-moistened with normal saline sterile were rolled over the various parts of the instrument to collect samples, and these were transported to the laboratory without any delay. These were inoculated in blood agar and incubated aerobically at $37^{\circ} \mathrm{C}$ overnight following which the colonies of microorganisms were identified using morphological character, gram staining and appropriate standard biochemical tests. Catalase, slide and tube coagulase positive Gram positive cocci with growth on Mannitol salt agar was identified as Staphylococcus aureus. The methicillin resistance (MRSA) of this organism was detected when the strain gave bluish colonies on using MeReSa CHROM Agar (Hi-media Laboratory).On the other hand the catalase, coagulase negative Gram positive cocci isolates were identified as coagulase negative Staphylococcus (CoNS). Gram negative oxidase negative catalase positive isolates were characterized as Enterobacterales and were further characterized using indole, urease, citrate, Triple sugar iron, Methyl red, VogesProskeuer and motility tests. Oxidase positive Gram negative bacilli were further identified by their pigmentation on nutrient agar, growth at different temperatures, amino acid fermentation and Oxidative Fermentative tests. Gram positive non sporing bacilli in palisading pattern were designated as diphtheroids and aerobic sporing Gram positive bacilli were termed as aerobic spore bearers. The data thus obtained were entered in Microsoft Excel format and tabulated by standard statistical techniques.

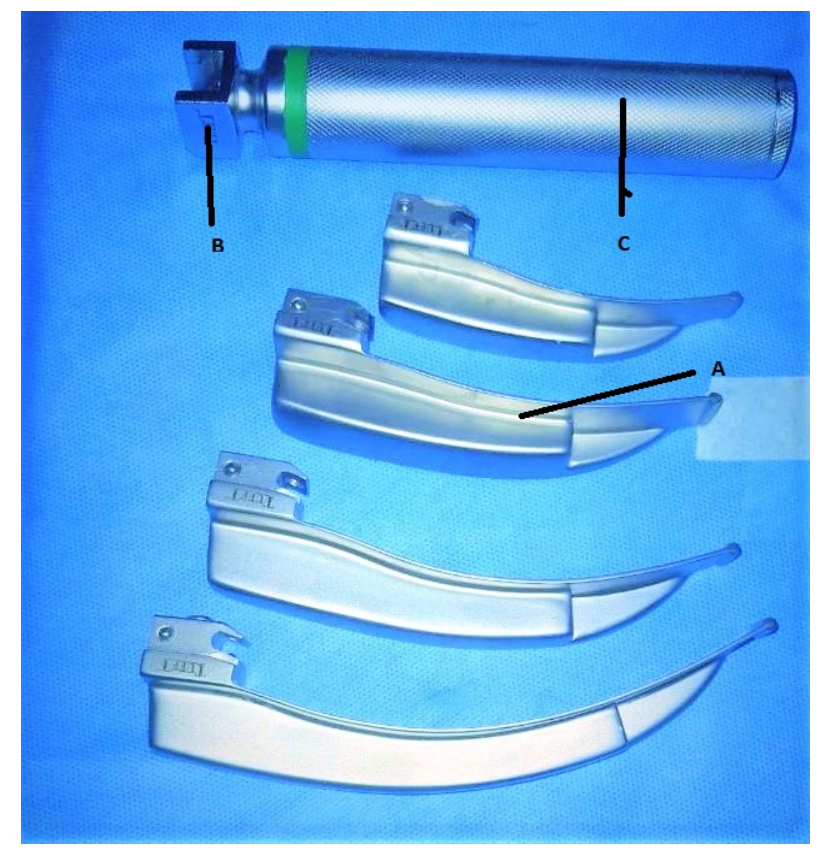

Figure 1. Largyngscope in crash cart designated with site of swab collection (A) surface of the blade, (B) front part of the handle top, and (C) front part of the handle's knurled surface.

\section{Result}

In the present study, 213 samples were obtained from various laryngoscopes from various areas of the hospital. This included 71 samples each from blade, handle top and knurled surface of the handle. The various areas from where the samples were collected are listed in Table 1. Maximum samples were collected from EICU (39.4\%) followed by SICU (18.3\%). Among the laryngoscopes included in the present study $32.4 \%$ were contaminated. The highest percentage of contaminated laryngoscopes belonged to Emergency followed by MICU. GICU had the lowest percentage of contaminated scopes.

The samples were collected from three different sites of the scope. 44 (61.9\%) of laryngoscopes were sterile in all the three sites. Swabs from blades were positive in $16.9 \%$ (12/71) cases, from light in 14.08\% (10/71) cases and from handle in $18.3 \%$ (13/71) cases. $\mathrm{P}$ value of difference of contamination of blade in comparison to handle is 0.89 (not significant at $\mathrm{p}<0.05$ )

Coagulase negative Staphylococcus was the commonest (37.1\%) pathogen isolated from different sites of the laryngoscopes followed by MSSA (22.9\%) and MRSA $(20 \%)$. Gram negative bacilli were uncommon contaminants on laryngoscopes with only 3 (8.6\%) strains of Pseudomonasspp. and 1 (2.9\%) strain of E.coli. (Table 2). 
Heavy microbial growth was present only in 1/12 i.e. $8.3 \%$ on blade. Heavy contamination was there only in $10 \%$ of upper part of handle and $40 \%$ of knurled surface of the handle. Heavy contaminating bacteria in bacteria consisted of CoNS while it was S.aureus including 2 MRSA strains in handle.

$45.7 \%$ of all the growths were scanty in amount. Heavy growth of organisms was there in only $22.9 \%$ of culture positives. Majority of these heavy growths were on part C i.e. knurled surface of handle but it was astonishing to find 1 blade showing heavy growth on blade even after high level disinfection. The heavy growth on blade consisted of CoNS while; $71.4 \%$ (5/7) of heavy growths on handle were S.aureusrest being CoNS. (Table3).

Table 1. Different sites of laryngoscope which were contaminated

\begin{tabular}{|c|c|c|c|c|c|}
\hline & \multirow{2}{*}{ Total no (\% total) } & Sterile (\% sterile ) & \multicolumn{3}{|c|}{ Contaminated scope as per site } \\
\cline { 3 - 6 } & & & A & B & C \\
\hline BICU & $10(14.08)$ & $2(20)$ & 1 & 0 & 1 \\
\hline GICU & $4(5.6)$ & $0(0)$ & 2 & 2 & 1 \\
\hline MICU & $9(12.7)$ & $4(44.4)$ & 2 & 2 & 3 \\
\hline NSICU & $7(9.9)$ & $4(57.1)$ & 1 & 2 & 1 \\
\hline SICU & $13(18.3)$ & $3(23.1)$ & 6 & 4 & 7 \\
\hline Emergency & $28(39.4)$ & $14(50)$ & 12 & 10 & 13 \\
\hline Total & 71 & 23 & & & 0 \\
\hline
\end{tabular}

Table 2. Organisms isolated from different sites of the laryngoscopes

\begin{tabular}{|c|c|c|c|c|}
\hline & A & B & $\mathbf{C}$ & Total (\% total) \\
\hline \multicolumn{5}{|c|}{ Potential pathogens } \\
\hline Staphylococcus aureus (MSSA) & 3 & 1 & 4 & $8(22.9)$ \\
\hline Staphylococcus aureus (MRSA) & 0 & 3 & 4 & $7(20)$ \\
\hline Escherichia coli & 1 & 0 & 0 & $1(2.9)$ \\
\hline Pseudomonas spp & 2 & 0 & 1 & $3(8.6)$ \\
\hline \multicolumn{5}{|c|}{ Potential contaminants } \\
\hline Coagulase negative Staphylococcus & 5 & 4 & 4 & $13(37.1)$ \\
\hline Aerobic spore bearers & 1 & 1 & 0 & $2(5.7)$ \\
\hline Diptheroid species & 0 & 1 & 0 & $1(2.9)$ \\
\hline Total & 12 & 10 & 13 & 35 \\
\hline
\end{tabular}

Table 3. Load of bacterial contamination in various sites

\begin{tabular}{|c|c|c|c|c|}
\hline & A & B & C & Total (\% Total) \\
\hline $\begin{array}{c}\text { Scanty } \\
(<\mathbf{5 c o l})\end{array}$ & 7 & 6 & 3 & $16(45.7)$ \\
\hline $\begin{array}{c}\text { Light } \\
(\mathbf{5 - 1 0} \text { col) }\end{array}$ & 3 & 3 & 3 & $09(25.7)$ \\
\hline $\begin{array}{c}\text { Medium } \\
(\mathbf{1 1 - 2 0} \text { col) }\end{array}$ & 1 & 0 & 1 & $02(5.7)$ \\
\hline $\begin{array}{c}\text { Heavy } \\
(>\mathbf{2 0} \text { col })\end{array}$ & 1 & 1 & 6 & $08(22.9)$ \\
\hline
\end{tabular}




\section{Discussion}

Appropriate disinfection of equipment is an important aspect to prevent cross infection. [2] Laryngoscopes are one such equipment which is used in operating theaters as well as in crash carts for intubation in emergency and ICUs of the hospital. Laryngoscope blade can damage the oral cavity and laryngeal mucosa of the patients thus favoring the cross transmission of bacteria and other infectious agents. These agents can further migrate to lungs causing diseases if appropriate hosts are encountered. The potential risk of a contaminated laryngoscope has been demonstrated since long [3- 5].

In the present study, 27/71 (38.1\%) of laryngoscopes were unsterile. Blades, Top of handle and knurled surface of handle were contaminated in $16.9 \%, 14.08 \%$ and $18.3 \%$ cases. In another similar study, contamination rates were comparable i.e. $18.2 \%$ for blades, $5.6 \%$ for handle tops, and $28.2 \%$ for handles' knurled surfaces. [6] On the other hand another study studying only contamination of handles found $100 \%$ of handles showing bacterial contamination. [7] This difference is because of the cleaning practices of laryngoscopes which vary between wards. In the present study, there was no significant difference in contamination of blade and handle of laryngoscope in contrast to other studies like Choi et al. [6] This can be explained by the fact that both the parts are cleaned and disinfected by the similar techniques for crash cart laryngoscopes in our hospital.

Laryngoscope blades are semi-critical items needing high-level chemical disinfectants like glutaraldehyde, hydrogen peroxide, ortho-phthalaldehyde, and peracetic acid with hydrogen peroxide and ethanol $>70 \%$. [8] Laryngoscope handles on the other hand do not come into direct contact with the patients' oropharyngeal mucosa during use thus lacks any guidelines for decontamination. The tip of the blade of the laryngoscope comes in contact with an area on the lower third of the handle ('contact point') in the 'off' position. Before and after use of laryngoscopes, the blade is generally folded along the length of the handle and kept. This contact point therefore presents a potential route for patient-to-patient transmission of blood and organisms from the oropharynx. $[1,7,9]$ Many studies have also confirmed that handles have a high potential to be contaminated by blood. $[10,11]$ Further the handles have fissured surface which are more difficult to clean thus have high propensity to harbor pathogenic microbes.

In the present study, the highest percentage of contaminated scopes was from Neurosurgical ICU and Emergency. Emergency crash carts as expected were the most used scopes as well. Other laryngoscopes were much less used and also had very low propensity of being unsterile. This may indicate improper handling in these places because of high patient thorough fare as well as improper cleaning. The cleaning and disinfection of the equipment are carried out at the same sector in which they are used by personnel allocated to take care of patients. Centralization of the cleaning process trained professionals for crash cart instruments has been recommended in previous studies. [12]This is particularly important for handle cleaning where there is no proper guideline and deviation in the processing protocol can result in the survival of microorganisms and increase the infection rate. A previous study by Chaskaret al [13] shows the difference in cleaning protocols and frequency of the laryngoscope handle and even blades for that matter. Further a work place based assessment of the staffs as suggested by Terry et al. [14] may be instituted which will ensure periodic evaluation of paramedical staff involved in cleaning and disinfection practices.

When the type of organism implicated in the unsterile scopes was considered, the highest percentage of organisms was Gram positive cocci while Gram negative bacilli constituted a small percentage of cases (4/35,11.4\%). In prior studies [13,15] Bacillus spp i.e aerobic spore bearers is the commonest isolated organism followed by CoNS while some studies also report CoNS as the commonest isolated organisms. Both these groups of organisms are contaminants. Thus improper packaging, storage, cleaning particularly of the knurled grooves which later form a potential reservoir for pathogens.

Majority (42.9\%) of the pathogens isolated were S.aureus with $46.7 \%$ of these being Methicillin resistant. Similar finding of Staphylococcus aureus as the most common pathogenic organism was also seen in other studies.[12] Staphylocococcus aureus and CoNS are important nosocomial pathogens. [16] Microorganisms that pose a risk to patients, such as Pseudomonas aeruginosa, Staphylococcus aureus have been found in other similar studies.[17,18] In 3 of these studies [17-19] microorganisms which are epidemiologically related to neonatal death were identified.

We found heavy growth in only one of the sample taken from blade revealing CoNS on culture while $71.4 \%$ of heavy growths on handle consisted of S.aureus (40\% of which was Methicillin resistant) This may be because of improper cleaning of handle and post cleaning improper packaging of the laryngoscopes. Further improper cleaning of the handle may leave organic residues like dried blood and saliva, as has been observed in other studies $[17,18]$ which may render the use of any further disinfectant ineffective.

Laryngoscopes in non OT crash carts is a potential source of bacterial contamination in the hospital because of improper cleaning at the area of use by untrained staffs and inadequate storage precautions following disinfection. Thus a centralized cleaning, disinfection as a whole instead of blade alone and proper packaging of this instrument will be useful. 


\section{REFERENCES}

[1] Esler M.D., Baines L.C., Wilkinson D.J., Langformd RM, "Decontamination of laryngoscopes: a survey of national practice”. Anesthesia, Vol. 54, No. 6, pp. 587-592, 1999, https://doi.org/10.1046/j.1365-2044.1999.00755.x.

[2] Rutala W.A., "Selection and use of disinfectants in health care”, in Mayhall CG, ed. Hospital Epidemiology and Infection Control, Baltimore: Williams \& Wilkins, 1996; pp. 913-936.

[3] Robert R.B., "Cleaning the laryngoscope blade”, Can AnaesthSoc J, Vol. 20, pp.241-244, 1973.

[4] Telang R., Patil V., Ranganathan P., Kelkar R., "Decontamination of laryngoscope blades: Is our practice adequate?” J Post Grad Med, Vol. 56, No. 4, pp. 257-261, 2010, DOI: 10.4103/0022-3859.70930

[5] Cullen M.M., Trail A., Robinson M., Keaney M., "Serratiamarcescens outbreak in a neonatal intensive care unit prompting review of disinfection of laryngoscopes" J HospInf, Vol. 59, No.1, pp. 68-70, 2004, DOI: 10.1016/j.jhin.2004.08.003

[6] Choi J.H., Cho Y.S., Lee J.W., Shin H.B., Lee I.K., "Bacterial Contamination and Disinfection Status of Laryngoscopes Stored in Emergency Crash Carts”, J Prev Med Public Health, Vol. 50, No. 3, pp. 158-164, 2017,doi: 10.3961/jpmph.17.013.

[7] Simmons S.A., "Laryngoscope handles a potential for infection”, AANA Journal, Vol. 68, No. 3, pp. 233-236, 2000.

[8] Rutala W.A., Weber D.J., Healthcare Infection Control Practices Advisory Committee (HICPAC), "Guideline for Disinfection and Sterilization in Healthcare Facilities, 2008; Update: May 2019” https://www.cdc.gov/infectioncontrol/ guidelines/disinfection.

[9] Yee K.F., "Decontamination issues and perceived reliability of the laryngoscope e a clinician's perspective”, AnaesthIntens Care, Vol. 31, No. 6, pp. 658-62, 2003, doi: 10.1177/0310057X0303100608.
[10] Morell R.C., Ririe D., James R.L., Crews D.A., Hoffstetler K., "A survey of laryngoscope contamination at a university and community hospital (letter)”, Anaesthesiology. Vol. 80, pp. 960, 1994.

[11] Phillips R.A., Monaghan W.P., "Incidence of visible and occult blood on laryngoscope blades and handles”, AANA J, Vol. 65, pp. 241-246, 1997.

[12] Negride Sousa A.C., Vilas Boas V.A., Levy C.E., Pedreira de Freitas M.I., "Laryngoscopes: Evaluation of microbial load of blades" Am J Infect Control, Vol. 44, No. 3, pp. 294-298, 2016, https://doi.org/10.1016/j.ajic.2015.10.014.

[13] Chaskar V.P., Dave N.M., Dias R., Karnik P., "Disinfection of laryngoscopes: A survey of practice”, Indian J Anaesth, Vol 61, No. 3, pp. 245-249, 2017, http://dx.doi.org/10.4103/ija.IJA_347_16.

[14] Terry D., Peck B., Gazula S. Workplace Based Assessment Program for International Medical Graduates: An Evaluation of an Australian Trial Site. Universal Journal of Public Health, Vol. 8, Issue 6, pp. 198-206, 2020, DOI: 10.13189/ujph.2020.080603

[15] Williams D., Dingley J., Jones C., Berry N., "Contamination of laryngoscope handles", J of Hospital Infect, 74, pp.123-128, 2010.

[16] Otta S., Bhoi P., Sahu K.K., Swain B., "Recent Trends in Sensitivity Pattern of Staphylococcus species”, Inter J of Cur Res and Rev, Vol. 13, No. 10, pp. S160-S165. DOI: http://dx.doi.org/10.31782/IJCRR.2021.SP259

[17] Foweraker J.E., "The laryngoscope as a potential source of cross infection” J Hosp Infect, Vol. 29, pp. 315-316, 1995.

[18] Neal T.J., Hughes C.R., Rothburn M.M., Shaw N.J., "The neonatal laryngoscope as a potential source of cross infection”, J Hosp Infect, Vol. 30, pp. 315-317,1995.

[19] Jones B.L., Gorman L.J., Simpson J., Curran E.T., McNamee S., Lucas C.et al, "A outbreak of Serratiamarcescens outbreak in two neonatal intensive care unit”, J Hosp Infect, Vol. 46, No. 4, pp. 314-319, 2000, DOI: 10.1053/jhin.2000.0837. 